Measurement of Factors Influencing the Relapse of Addiction: A

\title{
Factor Analysis
}

\author{
Abolhasan Afkar, ${ }^{1,2}$ Seyed Mahmoud Rezvani, ${ }^{3}$ and Abdolhosein Emami Sigaroudi ${ }^{1,4,}$ \\ ${ }^{1}$ Social Determinants of Health Research Center, Guilan University of Medical Sciences, Rasht, IR Iran \\ ${ }^{2}$ School of Health, Guilan University of Medical Sciences, Rasht, IR Iran \\ ${ }^{3}$ Guilan CDC, Manager at Guilan University of Medical Sciences, Rasht, IR Iran \\ ${ }^{4}$ Guilan Interventional Cardiovascular Research Center, Department of Cardiology, Heshmat Hospital, School of Medicine, Guilan University of Medical Sciences, Rasht, IR \\ Iran \\ "Corresponding author: Abdolhosein Emami Sigaroudi, Guilan Interventional Cardiovascular Research Center, Department of Cardiology, Heshmat Hospital, School of \\ Medicine, Guilan University of Medical Sciences, Rasht, IR Iran. Tel: +98 (13) 33328845, Fax: +98 (13) 33328843, E-mail: emamisig@gmail.com
}

Received 2015 August 08; Revised 2016 August 22; Accepted 2016 November 05.

\begin{abstract}
Background: Addiction is a primary, chronic disease of brain reward, motivation, memory and the related circuitry. Objectives: The purpose of the study was the measurement of effective components in addiction relapse, in Rasht city of Guilan province, Iran.

Patients and Methods: This study was done in 2014 that has been performed by using the factor analysis method. In the qualitative stage the process owners were 45 experts, and in the factor analysis stage they were 1850 people who were under treatment at addiction treatment centers. The data collection tool was a Researcher-Made Questionnaire whose content validity was determined through expert panel, and its construct validity was determined through exploratory factor analysis by principal component analysis method with varimax rotation using SPSS16 software.

Results: In exploratory component analysis, 4 main components were identified; Individual factors with 6 variables, $25.72 \%$ variance, and 17.81 eigenvalue as the most important factor, and Economic factors with 5 variables and 7.64\% variance as the less important factor, clarified the Addiction Relapse changes; however, in the fitted model which is the most completely saturated model, 4 factors of Individual factors with $\beta=0.48$, family factors with $\beta=0.23$, occupational factors with $\beta=0.2$, economic factors with $\beta=$ 0.12 had the highest predictive power in the order of importance.

Conclusions: According to the findings, individual, familial, social, cultural, and economic factors were the most important in relation to the addiction relapse.
\end{abstract}

Keywords: Factor Analysis, Measurement, Recurrence

\section{Background}

Substance abuse is a chronic and relapsing disorder with different genetic, mental, social and environmental factors influencing its commencement and continuation (1). Drug abuse is a disorder associated with an unhealthy pattern of drug consumption, and causes social problems for the individual. These problems include the lack of responsibility in the home, workplace and school or even legal problems for the individual $(2,3)$. It imposes a serious damage on the societies that could be social, economic, political, cultural or related to health. Health damages like hepatitis and AIDS can be transmitted by injecting drugs or having sexual contact. It also results in sociocultural damages like increased addiction-induced crimes such as theft, murder, self-immolation, joblessness, family rudeness, child abuse, increased separations, and the educational failure of students with addiction (4). Other studies have shown that family structure and peer socialization could be viewed as factors influencing the risk of problematic drug addiction. Drug addiction, therefore, creates negative effects not only on personal health, and on the cognitive and psychosocial abilities of the patients, but also on the life of the family members and the society at large (5). The annual report of WHO in 2008, indicated that about 200 million people in the world were addicted to opiates. According to this report, the highest prevalence rate of opiate abuse (2.8\%) was observed among Iranian people aged 15 - 64 (6). According to the investigations, almost $37 \%$ of the USA population, aged above 12 , have experienced the use of narcotic substances at least once, 5.5\% of whom have experienced the problems of substance abuse at least once during their lives (7). Statistical reports published by the international organizations, par- 
ticularly WHO, the international narcotics control board (INCB), and UNESCO (united nations educational scientific and cultural organization), suggest that drug abuse is increasing globally $(8,9)$. According to the national survey of drug and health in 2007, about 19.9 million of Americans aged over $12(8 \%)$ had at least once consumed a forbidden drug like marijuana, cannabis, cocaine, opium, heroin, hallucinogens, and inhalants a month before the study (9). According to estimates, the addicted population of Iran is 2 million people. The studies on addiction have reported the highest frequency of addicts in 20 - 35 age group (10). Despite the treatment advances, returning to heavy and uncontrollable use of such substances has still remained a prevalent problem. After removing toxins from the body and entering the rehabilitation interventions, most cases resume the substances almost 90 days after the beginning of such treatments. This is why all therapy methods emphasize the retention of treated cases today or, in other words, concentrate on relapse prevention (11). Considering the scientific fundamentals of this study, Fallahzade and Hosseini introduced having addicted friends, experiencing mental-spiritual stresses, returning to former places, confronting horrible situations, being rejected by family and friends, and observing the tools of substance use as the influential factors in the addiction relapse (12). According to Atadokht et al. (1998) only $20 \%$ to $50 \%$ of addicted cases can continue resisting the use of narcotic substances after one year (13). Although various studies were conducted on this subject, determining the elements of the relapse of addiction is not possible, because these elements vary depending on the diversity of use as well as economic, social, and cultural differences of the societies. Treatment conditions and personal/environmental characteristics influence the results of treatment. However, they can serve as the predictors of the lasting degrees of treatments. Therefore, the author decided to identify the factors influencing the relapse of addiction through conducting a qualitative study and Exploratory Factor Analysis (EFA).

\section{Objectives}

The purpose of the study was the Measurement of effective components of the Addiction Relapse.

\section{Methods}

This study is a descriptive-analytical research done in 2014 that has been performed by factor analysis method in two stages (cross-sectional and qualitative). In the qualitative stage, 45 experts were organized in 3 groups consisting of 15 experts with a master's degree or a higher one,
15 experts from Iran drug control headquarters, and $15 \mathrm{ex}$ perts from the Prisons Organization, the Police and the Judiciary who participated for the identification of the factors affecting the addiction relapse. Data collection tools at the qualitative stage were interview and questionnaire. The questionnaire had 8 Likert scale questions that were graded as completely agree (5), agree (4), no comment (3), disagree (2) and completely disagree (1). After determining the score for each component, the data was analyzed by SPSS 16 software (14). Then the agreement extent with each component was calculated among experts. Next, the components on which 70\% and more of experts had identical agreement, were chosen to be effective in the addiction relapse. At last, the rest of the components as well as the newly-proposed issues were negotiated again among those experts in order to reach a total agreement (14).

At the cross-sectional stage, the research society contained individuals who were under treatment in (Omid, Hayat-e-no, Bisetoun, Hedye Salamat, Hasti, Moein, Arash, Mehr, Kimiya, Golsa, Milad, Sa'adi, Rahayesh, Pouyan, Alghadir, Aramesh, Tavana, Baharan and Maani) addiction treatment centers. They were selected with the permission of the treatment deputy of Guilan University of Medical Sciences. These centers were selected randomly. At this stage, the data gathering tool was a questionnaire which consisted of two sections. Section one consisted of 10 questions about demographic information, and Section two consisted of 25 questions about the variables affecting the addiction relapse. Likert measurement method was used for marking every question with 5 degrees, so that 5 indicated "very much", 4 indicated "a lot", 3 indicated "average", 2 indicated "little" and 1 indicated "very little". The reliability of this questionnaire calculated by the test-retest method was 0.97 and the internal consistency was 0.96 using the Cronbach's Alpha method. Content validity was conducted by expert panel. Exploratory factor analysis was performed considering the eigenvalue and the value of the two measuring indicators of Kaiser-Meyer-Olkin (KMO) which was 0.97 and the significance of Bartlett's Test of Sphericity with $\mathrm{P}=0.01$ and the most important factors affecting the addiction relapse were identified through path analysis and structural equation modeling using LISREL software 8.8 (15).

\section{Results}

Out of 1850 participants, 1805 patients (98\%) were male and $45(2 \%)$ were female. In terms of marital status, 1356 patients $(73 \%)$ were married. $85 \%$ lived in urban regions. $29 \%$ of participants were 31 to 40 years old. In terms of employment, workers were 740 (40\%) who had the highest percentage and the students with 8 people $(0.5 \%)$ had 
the lowest percentage. In terms of education, $1.5 \%$ of the population were illiterate (The results of exploratory factor analysis: This stage is used for the identification of the most important and the most effective factors affecting the addiction relapse and the determination of the loading level of each variable on the principal factors. In this study, 4 factors were selected with eigenvalues higher than 1. These factors include: Individual factors with 6 variables and variance (25.72) and Eigenvalue (17.81), family factors with 7 variables and variance (17.32) and eigenvalue (5.43), Occupational factors with 7 variables and variance (13.5) and eigenvalue (4.27), economic factors with 5 variables and variance (7. 64) and eigenvalue (2.94) which in total was $65.18 \%$ of the variance of the scores (Table 2 ). The results of the confirmatory factor analysis: For the confirmation and the fitting of the factors obtained from exploratory factor analysis and the variables loaded under each factor, the data obtained from LISREL software 8.8 was used; in this stage, out of 34 variables of exploratory analysis, 9 variables were removed and 25 variables of the fitted model clarified the addiction relapse as variables which were loaded under the principal factors. For the fitting of which the following indicators have been used: Fit-index: 1) standardized root mean residual $(S M R)=0.044,2)$ root mean square error of approximation $($ RMSEA $)=0.08,3$ ) goodness fit index $(\mathrm{GFI})=0.97,4)$ adjusted goodness fit in$\operatorname{dex}(\mathrm{AGFI})=0.94 .5)$ comparative Fit index $(\mathrm{CFI})=0.97,6)$ incremental fit index $(\mathrm{IFI})=0.96,7)$ relative fit index $(\mathrm{RFI})$ $=0.96,8)$ normed fit index $(\mathrm{NFI})=0.97,9)$ non- normed fit index $(\mathrm{NNFI})=0.96$. In the fitted model which is the most completely saturated model, 4 factors of Individual factors with $\beta=0.48$, Family factors with $\beta=0.23$, Occupational factors with $\beta=0.2$, and Economic factors with $\beta=0.12$ had the highest predictive power in the order of importance (Figure 1).

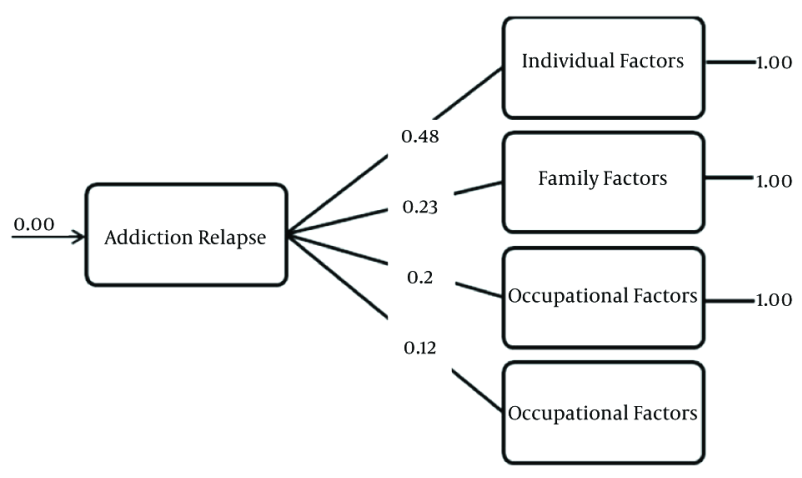

Figure 1. Addiction Relapse Fit Model
Table 1. Demographic Characteristics of the Patients

\begin{tabular}{|c|c|}
\hline Variable & No. (\%) \\
\hline \multicolumn{2}{|l|}{ Gender } \\
\hline Male & $1805(98)$ \\
\hline Female & $45(2)$ \\
\hline \multicolumn{2}{|l|}{ Age, $y$} \\
\hline$\leq 20$ & $18(1)$ \\
\hline $21-30$ & $499(27)$ \\
\hline $31-40$ & $530(29)$ \\
\hline $41-50$ & $370(20)$ \\
\hline $51-60$ & $335(18)$ \\
\hline$>60$ & $98(5)$ \\
\hline \multicolumn{2}{|l|}{ Marital Status } \\
\hline Married & $1356(73)$ \\
\hline Single & $430(23)$ \\
\hline Divorced/Separated & $64(4)$ \\
\hline \multicolumn{2}{|l|}{ Education } \\
\hline Illiterate & $30(1.5)$ \\
\hline ptimary school & $319(17)$ \\
\hline Middle school & $620(33.5)$ \\
\hline High school & $593(32)$ \\
\hline Academic & $288(16)$ \\
\hline \multicolumn{2}{|l|}{ Region } \\
\hline Urban & $1572(85)$ \\
\hline Rural & $278(15)$ \\
\hline \multicolumn{2}{|l|}{ Occupation } \\
\hline Student & $8(0.5)$ \\
\hline College students & $109(6)$ \\
\hline Housekeeper & $37(2)$ \\
\hline Soldier & $8(0.5)$ \\
\hline Manual worker & $740(40)$ \\
\hline Farmer & $168(9)$ \\
\hline Shopkeeper & $150(8)$ \\
\hline Employee & $130(7)$ \\
\hline Retired & $68(4)$ \\
\hline Unemployed & $432(23)$ \\
\hline
\end{tabular}

\section{Discussion}

EFA results identified 4 determinant factors for the relapse of addiction among which individual factors with 5 variables were the most influencing component. The most important variables in this category are: the presence of 
Table 2. Factor loading, Cronbach's Alpha, Variance, Eigenvalue and Intraclass Correlation Coefficient for the Modified 4 Factor Correlated Model

\begin{tabular}{|c|c|c|c|c|c|}
\hline Items & FL & CA & ICC & VAR & $\mathbf{E V}$ \\
\hline Individual factors & & 0.83 & 0.91 & 25.72 & 17.81 \\
\hline 2. Addicted friends & 0.89 & & & & \\
\hline 14. Abundance of drugs & 0.83 & & & & \\
\hline 6. Addicted partners & 0.78 & & & & \\
\hline 21. Death of spouse & 0.75 & & & & \\
\hline 13. Rejection from friends & 0.73 & & & & \\
\hline 10. Being single & 0.71 & & & & \\
\hline Family factors & & 0.89 & 0.94 & 18.32 & 5.43 \\
\hline 25. A first-degree relative's addiction & 0.86 & & & & \\
\hline 3. A second-degree relative's addiction & 0.83 & & & & \\
\hline 11. Death of parents & 0.81 & & & & \\
\hline 5. Divorce & 0.80 & & & & \\
\hline 7. Discrimination in the family & 0.73 & & & & \\
\hline 12. Illiterate parents & 0.68 & & & & \\
\hline \multicolumn{6}{|l|}{ 4. Family congestion } \\
\hline Occupational factors & & 0.78 & 0.83 & 13.5 & 4.27 \\
\hline 1. Unemployment & 0.82 & & & & \\
\hline 15. Occupational exposure to opiates & 0.81 & & & & \\
\hline 17. Job loss & 0.79 & & & & \\
\hline 23. Long and tedious work & 0.75 & & & & \\
\hline 18. Long time driving & 0.69 & & & & \\
\hline 9. Dissatisfaction with job & 0.66 & & & & \\
\hline 24.Failure in Jobs & 0.63 & & & & \\
\hline \multicolumn{6}{|l|}{ Economic factors } \\
\hline 8. Poverty & 0.87 & 0.80 & 0.91 & 7.64 & 2.94 \\
\hline 19. Bankruptcy & 0.77 & & & & \\
\hline 22.Cheap opiates & 0.72 & & & & \\
\hline 20. Earning money & 0.68 & & & & \\
\hline 16. Wealth & 0.67 & & & & \\
\hline
\end{tabular}

Abbreviations: CA, Cronbach's Alpha; FL, factor loading; ICC, interclass correlation; VAR, variance; EV, eigenvalue.

addicted and depraved friends, substance availability, being rejected by friends, addicted coworkers, divorce and death of spouse. The study by Deborah identified individual factors as one of the most important elements with a crucial role in the relapse of addiction in the referrals to addiction treatment centers (6). This agrees with our study. Gokcearslan et al. concluded that the vast majority of addicted cases were young people. Addicted cases believe that unfit friends, poverty and entourage are important factors influencing the use of substance after quitting
(12). This also agrees with our study. To explain this finding more, it can be argued that puberty problems, identity crisis, and mental and spiritual conditions of adolescents on the one hand, and weak social relations, lack of social control and social confusion on the other hand, pave the way for the appearance of the individual factors. It seems that people who give up addiction still experience its side effects such as physical pains and mental disorders. Therefore, suitable therapies to mitigate the pains and psychological treatments in related treatment centers 
are of high importance. As an internal stimulator, however, unseemly mood and depression can encourage addicted cases to resume narcotic substances. Since the vast majority of addicted people believe that they should reuse the substances in order to get rid of unseemly mood and depression, interventions on modifying this belief and replacing more efficient beliefs seem necessary.

FEA identified familial factors, with 6 variables and eigenvalue of 5.43, as the second important component. The variables of this category are: the first and the second degree relatives' addiction, father's and mother's death, discrimination in the family, parents' illiteracy and being in a crowded family. Also, Atadokht et al. reported the role of family expressed emotion and perceived social support in predicting the addiction relapse. The result of this study showed a positive relationship between family expressed emotions and the frequency of relapse, and a significant negative relationship between perceived social support and the frequency of relapse (13). In 2001 Sachman showed that there is a direct relation between parents' addiction, especially mothers', and the child's addiction. However, the mother's addiction causes her to neglect her child which in turn results in the increased relapse of addiction in such families (16). Nastizaei introduced in his study the discriminations and disputes in families as important factors affecting the relapse of addiction. He believes that family, as the primary center of education and the founder of an individual's personality, plays a crucial role in the prevention of this inauspicious phenomenon (17). To analyze this finding more, one can argue that the family is an element with a remarkable influence on the formation of the personality of the children and the adolescents. Therefore, parents should regulate their relations with children more accurately. They should always observe the principle of esteem and consider related constraints in their relations with children. With 7 variables, variance of $18.32 \%$, and eigenvalue of 4.27 , occupational factors were identified as the third influential factors. According to the findings, occupational factors influence the relapse of addiction. Therefore, it is necessary to design studies by concentrating on solving or mitigating joblessness problems, creating job opportunities, inspecting laborers' and employees' work conditions, avoiding contact with opium due to occupational conditions, and adjusting work hours as preventive actions against the relapse of addiction. In 2004, the findings of Sadeghiahari et al. showed that 56 cases out of 103 studied cases returned to addiction during the first 1-3 months after quitting it. They stated occupational conditions as the main cause of the relapse of addiction, which agrees with this study (18). The results of another study suggested that the grungy environment of life affects the relapse of addiction, i.e. environments where opium and drugs are easily accessible and the social network of friends who support and encourage the continuation of substance use is present (19). To explain this finding, it can be argued that in the environments where narcotic substances are easily accessible people may have more opportunity to commit substancerelated crimes. The reason is that such environments provide people with more opportunities to commit substancerelated crimes. This in turn paves the ground for the relapse of addiction. The fourth influential factors were economic factors with 5 variables and confirmed variance of 7.64\%. According to another study, as an economic factor, life costs have a remarkable influence on the relapse of addiction that is in concordance with the current study (9). However, the results of another study showed that in the western countries, death phobia and getting tired of addiction are the main causes motivating people to give up addiction (20). This finding does not agree with our study. To explain this finding more, it can be argued that although financial poverty, life costs and bankruptcy have a remarkable influence on the relapse of addiction, wealth can serve as an influential factor on the relapse of addiction, too. Limitations of this study included the lack of the cooperation of some outpatient treatment centers and addicts in filling the related questionnaire. According to the findings, it is not enough as only one factor in the addiction relapse. But addiction relapses were made with different ratios of individual, familial, social, cultural and economic factors. In order to prevent the relapse, we need a study on the design of the proper method. Factors influencing the relapse of addiction were compared with other reports in the viewpoint of factor type and addiction type as shown in Table 3. This comparison shows that the factors influencing the relapse of addiction are different from one country to another one, and also they depend on the addiction type and such parameters.

\section{Acknowledgments}

We wish to thank all the staff in Omid, Hayat-e-no, Bisetoun, Hedye Salamat, Hasti, Moein, Arash, Mehr, Kimiya, Golsa, Milad, Sa'adi, Rahayesh ,Pouyan, Al-ghdir, Aramesh, Tavana, Baharan, and Maani centers who collaborated with us in doing this research.

\section{Footnotes}

Authors' Contribution: The first author developed the original idea and contributed in a significant manner. The second author participated in the revision of the manuscript and performed parts of the analysis and the interpretation of the data, drafting, revising, and approving 
this manuscript. All authors read and approved of the final manuscript. Financial Disclosure: None declared. Funding/Support: The financial support was provided by the department of health of Guilan University of Medical Sciences (Project No.2838).

Financial Disclosure: None declared.

Funding/Support: The financial support was provided by the department of health of Guilan University of Medical Sciences (Project No.2838).

\section{References}

1. Brady KT, Sinha R. Co-occurring mental and substance use disorders: the neurobiological effects of chronic stress. Am J Psychiatry. 2005;162(8):1483-93. doi: 10.1176/appi.ajp.162.8.1483. [PubMed: 16055769].

2. Drake RE, Wallach MA, McGovern MP. Future directions in preventing relapse to substance abuse among clients with severe mental illnesses. Psychiatr Serv. 2005;56(10):1297-302. doi: 10.1176/appi.ps.56.10.1297. [PubMed: 16215199].

3. Mokhber N, Asgharipour N, Bananaj A. Frequency of harmful behaviors in patients who are suffering from substances abuse. Int J High Risk Behav Addict. 2012;1(3):132-6. doi: 10.5812/ijhrba.7403. [PubMed: 24971250].

4. Momeni F, Moshtagh Bidokhti N, Porshahbaz A. The effectiveness of cognitive-behavioral group therapy on reduction of craving, depression and anxiety symptoms among the opiate abusers under MMT. $J$ Res Addict. 2009;3(11):83-98.

5. Ruchiwit M. Effects of a Three-Stage Intervention Program on the Holistic Health Status of Patients with Drug Addiction after Discharge. Nurs Midwifery Stud. 2013;1(3):120-7. doi:10.5812/nms.10077.

6. Deborah AO. Psychiattric nursiry Bioao Jical and Behoavioral concepts. Philadolphia: Sanders; 1995.

7. Atkinson RM. Substance Abuse. In: Coffee CE, Cummings JL, editors. Textbook of Geriatric Neuropsychiatry. Washington DC: American Psychiatric Press; 2000. p. 367-400.

8. Ornstein TJ, Iddon JL, Baldacchino AM, Sahakian BJ, London M, Everitt BJ, et al. Profiles of cognitive dysfunction in chronic amphetamine and heroin abusers. Neuropsychopharmacology. 2000;23(2):113-26. doi: 10.1016/S0893-133X(00)00097-X. [PubMed:10882838].

9. Afkar A, Mehrabian F, Omidi-Khalky S, Mahboubi M. Drug abuse Pattern and Frequency of High Risk Be-haviors the Clients to Outpatient Addiction Treatment Centers. J Biol Today's World. 2014;3(4):94-9.

10. Abbasi A, Taziki A, Moradi A. Drug abuse pattern based on demographic factors in referring drug users in Gorgan.J Gorgan Univ Med Sci. 2006;8(1):22-7.

11. Asghari A, Porshahbaz A, Farhodian A. Personality dimensions relevant to substance abuse relapse in the treatment of opioid dependence with methadone. J Res Addict. 2011;5(19):20-7.

12. Gokcearslan E, Ozgur O, Akgun R. Social service need for the treatment of alcohol and substance addiction "amatem case". Int J Acad Res. 2011;3(2).
13. Atadokht A, Hajloo N, Karimi M, Narimani M. The role of family expressed emotion and perceived social support in predicting addiction relapse. Int J High Risk Behav Addict. 2015;4(1). ee21250. doi: 10.5812/ijhrba.21250. [PubMed: 25883918].

14. Nasiripour AA, Afkar A, Tabibi J, Najafi L, Kmali M, Farmanbar R. Designing community based rehabilitation model using structural equation modeling (Iran). Int Res J Med Sci. 2013;1(8):1-7.

15. Joreskog KG, Sörbom D. LISREL 8.80 for Windows [Computer software]. Lincolnwood: Scientific Software International; 2006.

16. Suchman NE, Luthar SS. The Mediating Role of Parenting Stress in Methadone-Maintained Mothers' Parenting. Parent Sci Pract. 2001;1(4):285-315. [PubMed: 17710214].

17. Nastizayi N, Hezareh Moghadam M, Mollazehi A. The study of factors for recurred addiction from the view of self-introduced addicts to the addiction abandonment centers of zahedan. J Urmia Nurs Midwifery Faculty. 2010;8(3).

18. Sadegiye Ahari S, Azami A, Barak M, Amani F, Firuz S. Reviewing the causes of recurred addiction in patients who referred to centers introduced of Tehran welfare. Ardabil Med Univ J. 2004;3(4):36-40.

19. Caprioli D, Celentano M, Paolone G, Badiani A. Modeling the role of environment in addiction. Prog Neuropsychopharmacol Biol Psychiatry. 2007;31(8):1639-53. doi: 10.1016/j.pnpbp.2007.08.029. [PubMed: 17889978].

20. Garrity JF. Jesus, peyote, and the holy people: alcohol abuse and the ethos of power in Navajo healing. Med Anthropol Q. 2000;14(4):521-42. [PubMed: 11224979].

21. Mattoo SK, Chakrabarti S, Anjaiah M. Psychosocial factors associated with relapse in men with alcohol or opioid dependence. Indian J Med Res. 2009;130(6):702-8. [PubMed: 20090130].

22. Abdollahi Z, Taghizadeh F, Hamzehgardeshi Z, Bahramzad O. Relationship between addiction relapse and self-efficacy rates in injection drug users referred to Maintenance Therapy Center of Sari, 1391. Glob J Health Sci. 2014;6(3):138-44. doi: 10.5539/gjhs.v6n3p138. [PubMed: 24762356].

23. Sharma AK, Upadhyaya SK, Bansal P, Nijhawan M, Sharma DK. A study of factors affecting relapse in substance abuse. Education. 2012;2(17.033):17.033.

24. Nazari I, Jamshidi F, Rahimi Z, Cheraghi M. Effective factors of addiction relapse among self-introducing addicts to drug addictionquitting centers in Khuzestan Province, Iran; 2015. Int J Manag Human Sci. 2014;3(6):2231-9.

25. Mirzaei T, Ravary A, Hanifi N, Miri S, Oskouie F, Mirzaei Khalil Abadi S. Addicts' perspectives about factors associated with substance abuse relapse. Iran J Nurs. 2010;23(67):49-58.

26. Rimaz S, Mohseni S, Merghati Khoei ES, Dastoorpour M, Akbari F. Casecontrol study of factors influencing on drug abuse relapse in addicts referred to two recovery centers in Tehran. J School Public Health Inst Public Health Res. 2013;10(3):53-64.

27. Afsar A, Bashirian S, Poorolaja J, Hazavehei SM, Vatan Nawaz E, Zinat Motlagh F. Predictive factors of relapse among patients treated with methadone maintenance treatment referred to addiction centers in Hamadan based on health belief model. J Health Syst Res. 2014;9(14):2034-45. 


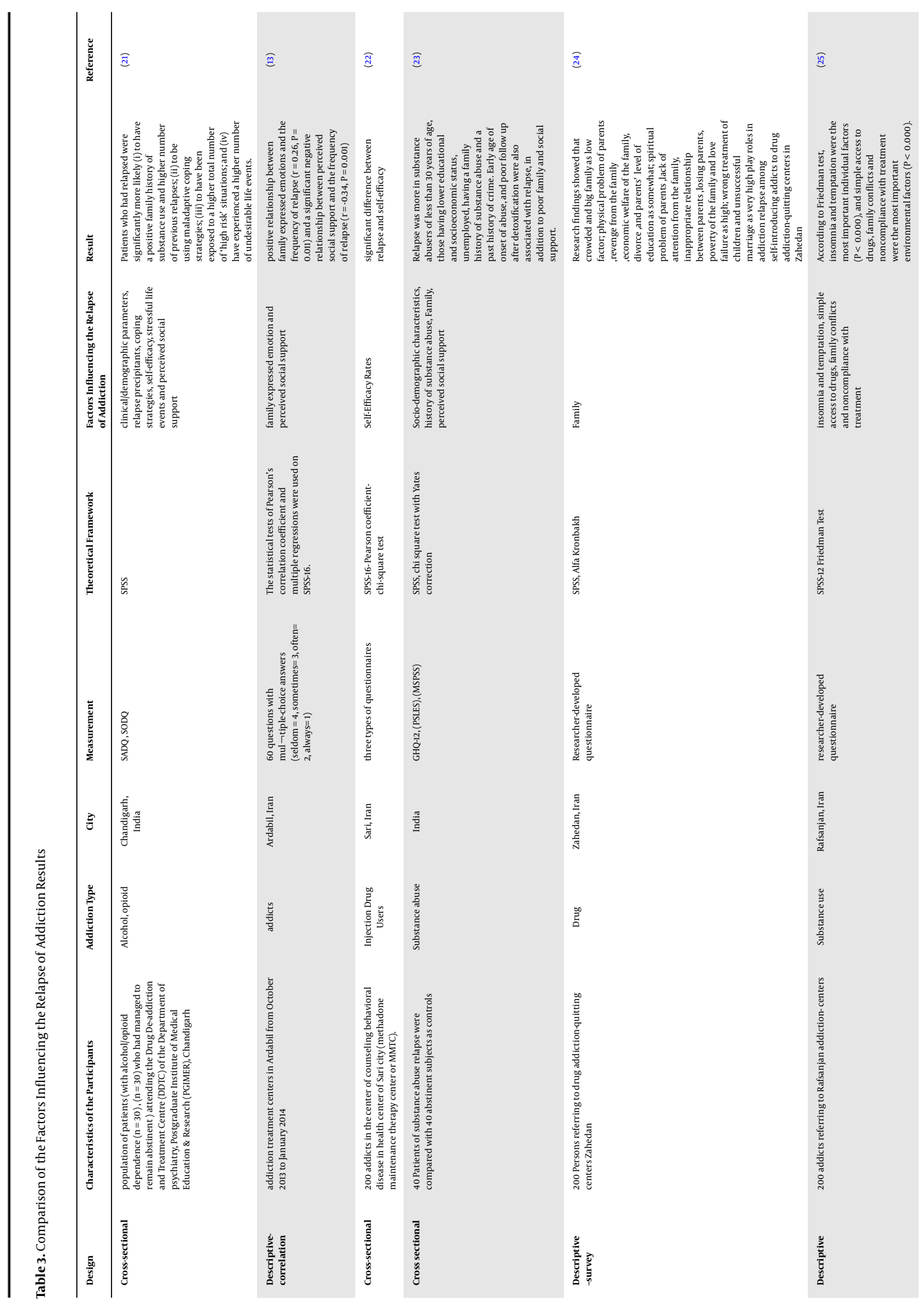




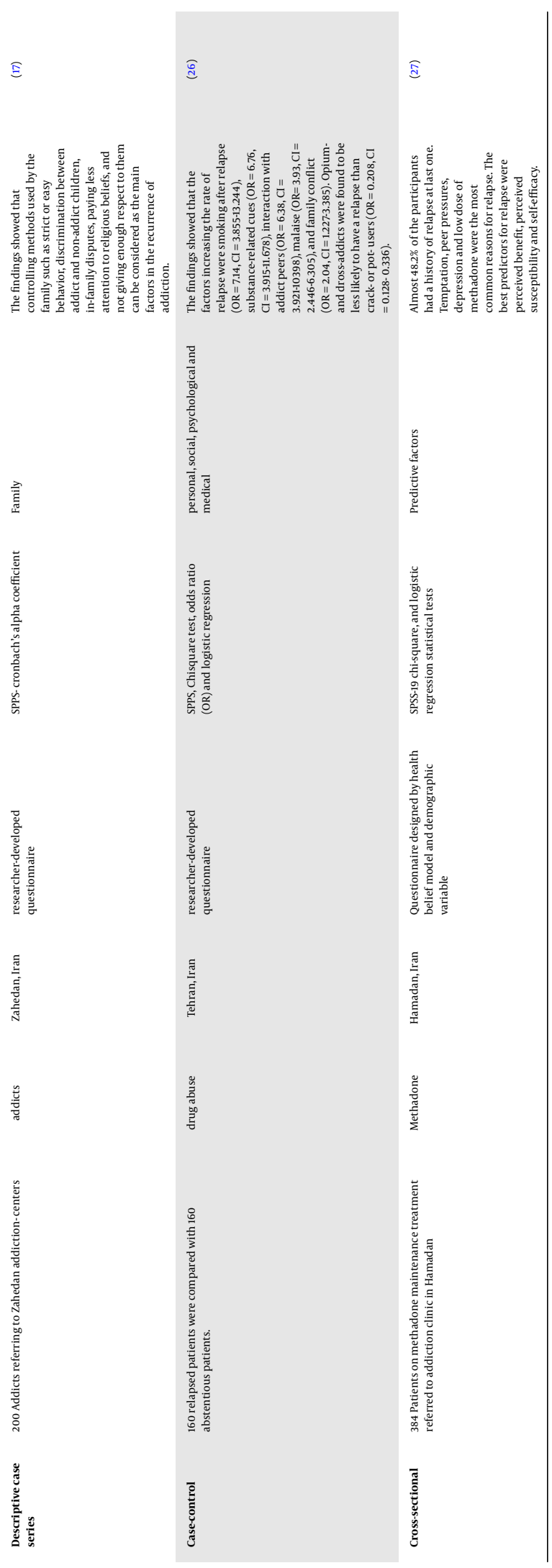

